\title{
Differential Conduction Velocity Regulation in Ipsilateral and Contralateral Collaterals Innervating Brainstem Coincidence Detector Neurons
}

\author{
Armin H. Seidl, ${ }^{1,2}$ Edwin W Rubel, ${ }^{1,2,3}$ and Andrés Barría ${ }^{1,3}$ \\ ${ }^{1}$ Virginia Merrill Bloedel Hearing Research Center, and Departments of ${ }^{2}$ Otolaryngology-Head and Neck Surgery, and ${ }^{3}$ Physiology and Biophysics, \\ University of Washington, Seattle, Washington 98195
}

Information processing in the brain relies on precise timing of signal propagation. The highly conserved neuronal network for computing spatial representations of acoustic signals resolves microsecond timing of sounds processed by the two ears. As such, it provides an excellent model for understanding how precise temporal regulation of neuronal signals is achieved and maintained. The well described avian and mammalian brainstem circuit for computation of interaural time differences is composed of monaural cells in the cochlear nucleus (CN; nucleus magnocellularis in birds) projecting to binaurally innervated coincidence detection neurons in the medial superior olivary nucleus (MSO) in mammals or nucleus laminaris (NL) in birds. Individual axons from CN neurons issue a single axon that bifurcates into an ipsilateral branch and a contralateral branch that innervate segregated dendritic regions of the MSO/NL coincidence detector neurons. We measured conduction velocities of the ipsilateral and contralateral branches of these bifurcating axon collaterals in the chicken by antidromic stimulation of two sites along each branch and whole-cell recordings in the parent neurons. At the end of each experiment, the individual $\mathrm{CN}$ neuron and its axon collaterals were filled with dye. We show that the two collaterals of a single axon adjust the conduction velocities individually to achieve the specific conduction velocities essential for precise temporal integration of information from the two ears, as required for sound localization. More generally, these results suggest that individual axonal segments in the CNS interact locally with surrounding neural structures to determine conduction velocity.

Key words: conduction velocity regulation; myelin plasticity; sound localization

\section{Introduction}

Binaural processing, using the information from both ears, is essential for the segregation of sounds and the ability to isolate signals in noisy environments, called the "cocktail party effect." The cellular basis of this ability is a circuit of neurons, conserved from reptiles to humans (Ashida and Carr, 2011; Wang et al., 2013), that encodes microsecond time differences in sounds reaching the two ears, interaural time differences (ITDs), and computes the locations of sound. In addition to being important in its own right, this system serves as a useful model for understanding how precise timing of electrical signals is achieved in the CNS.

Excitatory projections from monaurally innervated neurons in the cochlear nucleus on each side of the brain project to an array of binaurally innervated coincidence detector neurons.

\footnotetext{
Received Dec. 31, 2013; revised Feb. 20, 2014; accepted Feb. 28, 2014

Author contributions: A.H.S., E.W.R., and A.B. designed research; A.H.S. performed research; A.H.S. analyzed data; A.H.S., E.W.R., and A.B. wrote the paper.

This work was supported by the Virginia Merrill Bloedel Mini Grant Program, the National Organization for Hearing Research, and National Institutes of Health Grants DC011343, DC03829, and DC04661. We thank Jane M. Sullivan, Deda C. Gillespie, Ben A. Barres, David J. Perkel, Jennifer L. Thornton, Melissa L. Caras, Jason Tait Sanchez, and Claire J. Creutzfeldt for comments on the manuscript.

The authors declare no competing financial interests.

Correspondence should be addressed to Armin H. Seidl, Virginia Merrill Bloedel Hearing Research Center, University of Washington, Box 357923, Seattle, WA 98195-7923. E-mail: armins@uw.edu.

DOI:10.1523/JNEUROSCI.5460-13.2014

Copyright $\odot 2014$ the authors $\quad 0270-6474 / 14 / 344914-06 \$ 15.00 / 0$
}

Temporal precision of acoustically evoked signals from both ears must be precisely guaranteed, as ITDs from sound sources along the azimuth may differ by only a few microseconds (Goldberg and Brown, 1969; Carr and Konishi, 1990; Yin and Chan, 1990; Köppl and Carr, 2008). In the avian auditory brainstem, neurons in nucleus magnocellularis (NM) receive sound information from the ipsilateral ear and project myelinated excitatory axons to an array of coincidence detector neurons in nucleus laminaris (NL) on both sides of the brain (Parks and Rubel, 1975; Rubel and Parks, 1975; Carr and Konishi, 1990). Soon after exiting the soma, the NM axon branches to form two major collaterals; hence, a single NM axon provides both ipsilateral and contralateral excitatory inputs to NL neurons (Fig. 1A). A "delay line," contributed by the contralateral collateral, provides the temporal delays to NL neurons required for a bilateral map of soundsource locations (Fig. 1A; Jeffress, 1948; Young and Rubel, 1983; Carr and Konishi, 1990; Overholt et al., 1992; Köppl and Carr, 2008). Sounds originating from straight ahead ( $0^{\circ}$ azimuth) elicit action potentials (APs) simultaneously in neurons of both NMs. These signals must be conveyed to a medial location in the NL map within a microsecond time window to encode this $0 \mu$ ITD position (Fig. 1A, yellow neuron; Young and Rubel, 1983; Overholt et al., 1992).

Recent length measurements of individual axon collaterals from NM neurons to NL on each side of the brain revealed large 

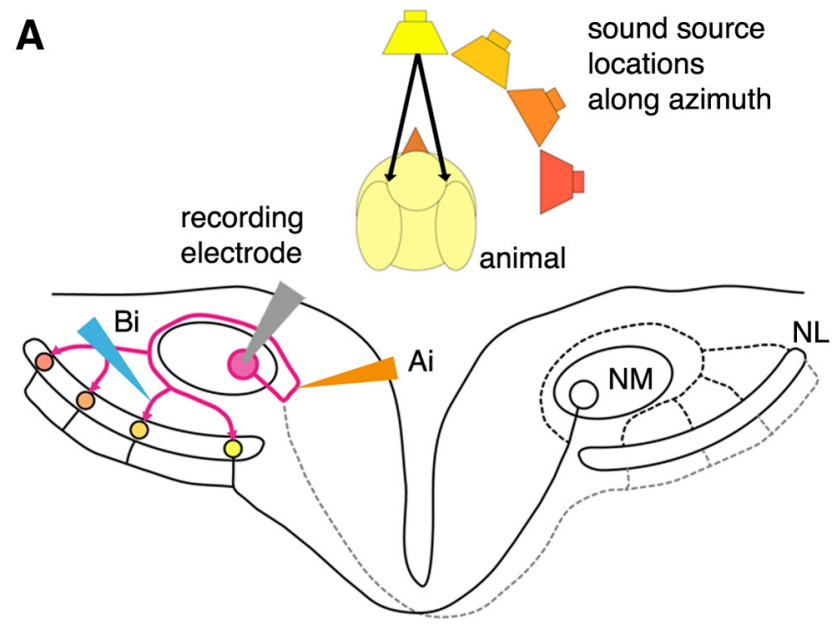

B

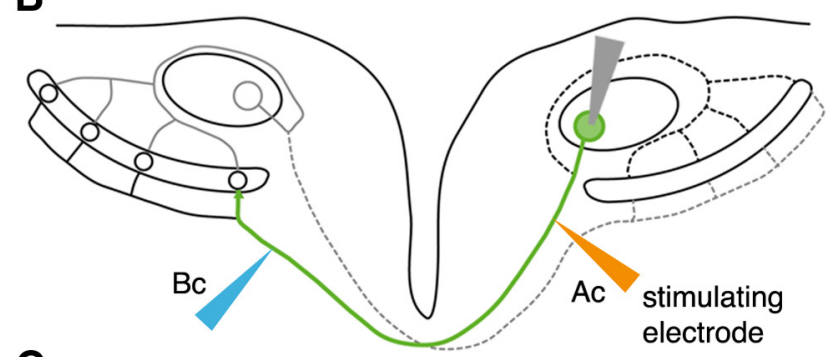

C

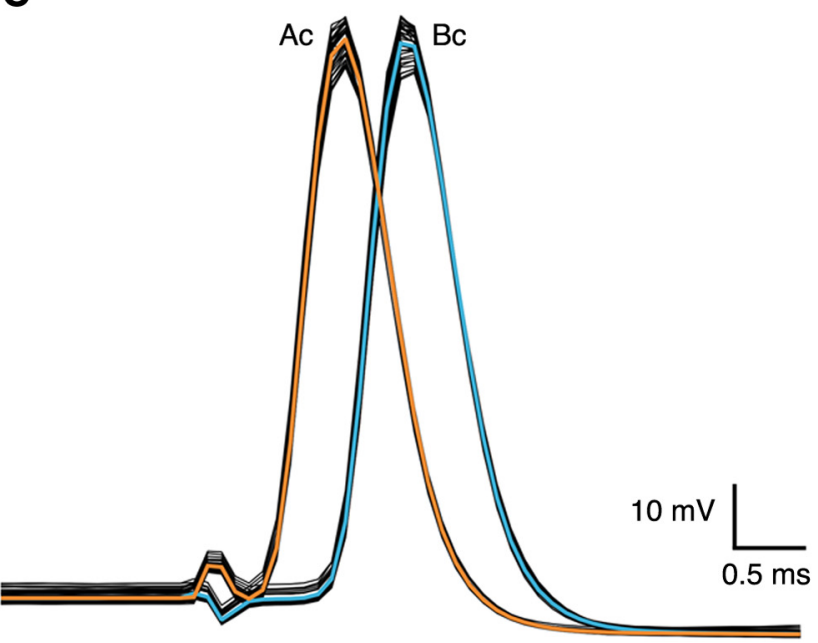

Figure 1. Schematic of circuit and recording. $A, B$, NM neurons on each side of the brain receive inputs from the ipsilateral ear. Each NM neuron projects both to the ipsilateral NL and to the contralateral NL. The inputs from NM to the ipsilateral NL are similar in length and display similar conduction times. The inputs to the contralateral NL establish a delay line on the ventral side of the NL cell bodies. This circuit embodies a modified Jeffress model of sound localization with a delay line on one side of the coincidence detector array. Antidromic action potentials were elicited either along the ipsilateral axon segment $(\boldsymbol{A}$, magenta, stimulating points $\mathrm{Ai}$ and $\mathrm{Bi}$ ) or along the contralateral segment ( $\boldsymbol{B}$, green, stimulating points $\mathrm{Ac}$ and $\mathrm{BC}$ ) and recorded in NM neurons. $C$, Sample traces of antidromic action potentials elicited by two different stimulating electrodes placed as indicated in $\boldsymbol{B}$ and recorded in the same neuron. The average trace is shown in color. The time difference between the peaks of these two aAPs was measured and used to calculate conduction velocity. Experiments were performed at RT $\left(21.5-22.8^{\circ} \mathrm{C}\right)$ unless otherwise indicated.

differences in the actual lengths of the ipsilateral versus contralateral collaterals (Seidl et al., 2010). Hence, at naturally occurring ITDs, axon length alone cannot be a sufficient substrate for coincident arrival of inputs at any of the NL neurons. Our results present evidence for differential regulation of conduction veloc- ities in the primary branches of the NM axon collaterals. This achieves isochronous signal propagation in axonal branches of different length, allowing coincidence detection as required for sound segregation.

\section{Materials and Methods}

Animals. Fertilized eggs of White Leghorn chickens (Gallus domesticus) were incubated at $37^{\circ} \mathrm{C}$ for $21 \mathrm{~d}$. All procedures were approved by the University of Washington Institutional Animal Care and Use Committee and conformed to National Institutes of Health guidelines.

Slice preparation. Acute brainstem slices were prepared from chickens of either sex at embryonic day 21 (E21) before hatching, as previously described (Sanchez et al., 2011). Slices were cut in the coronal plane at $300 \mu \mathrm{m}$ on a Microslicer DTK-Zerol vibratome (Ted Pella).

Slices were stored in a holding chamber and allowed to equilibrate for $30 \mathrm{~min}$ at $35^{\circ} \mathrm{C}$ in oxygenated ACSF. Slices were allowed to cool to room temperature (RT) for at least 15 min before being transferred from the holding chamber to a $0.5 \mathrm{ml}$ recording chamber, mounted on an Olympus BX51W1 microscope for electrophysiological experiments.

Physiology and stimulation. Before recording, two bipolar stimulating electrodes (custom made; tip size: inner pole, $12.5 \times 100 \mu \mathrm{m}$; outer pole diameter, $125 \mu \mathrm{m}$; FHC) were placed along the trajectory of NM axons on either the ipsilateral loop (Fig. 1A), or ipsilateral and contralateral of the midline to stimulate the contralaterally projecting axon collateral (Fig. 1B). The tips of the electrodes were coated with $\mathrm{DiO}$ (Biotium) to visualize the stimulation site. The center of the $\mathrm{DiO}$ labeling was defined as the stimulation site.

Whole-cell electrophysiology current-clamp experiments were performed using an Axon Multiclamp 700B amplifier (Molecular Devices) at room temperature $\left(21.5-22.8^{\circ} \mathrm{C}\right)$ unless noted otherwise. Patch pipettes were pulled to a tip diameter of $1-2 \mu \mathrm{m}$ and had resistances ranging from 3 to $6 \mathrm{M} \Omega$. Pipettes were filled with a standard potassium-based internal solution (Sanchez et al., 2012). Additionally, the internal solution contained $0.5 \%$ biocytin (Sigma-Aldrich) to label the axon collaterals from which conduction velocity data were obtained. All experiments were conducted in the presence of the $\mathrm{GABA}_{\mathrm{A}}$ receptor antagonist picrotoxin $(100 \mu \mathrm{M})$, the NMDAR antagonist DL-APV $(100 \mu \mathrm{M})$ and the AMPAR antagonist NBQX $(20 \mu \mathrm{M})$. Square electric pulses, $5 \mu \mathrm{s}$ in duration, were delivered through an ISO-Flex flexible stimulus isolator (A.M.P.I.) and interval generator (S88, Grass Technologies). Stimulus intensity was gradually adjusted until responses were reliably elicited.

As our experiments were conducted at room temperature, it was important to estimate the actual conduction velocities of the NM collaterals under physiological conditions. Toward that end, we determined the temperature coefficient (Q10) for NM axons. We stimulated the contralateral NM axon ipsilateral of the midline with a single bipolar electrode, as described above, and recorded antidromic APs (aAPs) at temperatures ranging from 24 to $32^{\circ} \mathrm{C}$. We normalized the relative conduction velocity to 1 for the lowest temperature measured. The value for Q10 along NM axons was determined using the standard equation shown as follows:

$$
Q_{10}=\left(\frac{R_{2}}{R_{1}}\right)^{\left(\frac{10}{T_{2}-T_{1}}\right)},
$$

where $R$ is conduction velocity and $T$ is temperature.

Axon visualization. After a successful recording, which usually lasted 25-30 min, the slice was incubated in oxygenated ACSF at RT for another $30 \mathrm{~min}$ and then fixed in $4 \%$ paraformaldehyde in PBS at $4^{\circ} \mathrm{C}$ for $12 \mathrm{~h}$. Slices were rinsed in PBS and subsequently exposed to 1:1000 Alexa Fluor 594 streptavidin (Invitrogen) in 0.3\% Triton X-100 (Sigma) for at least $24 \mathrm{~h}$. Slices were rinsed in PBS again, coverslipped using Glycergel (Dako), and imaged using a confocal microscope (Fluoview 1000, Olympus). Using the resulting three-dimensional (3-D) images, labeled axons were reconstructed with Neurolucida (MBF Bioscience), and the distance between stimulation sites along the axon was measured.

Data analysis. Recording protocols were written and run using Clampex acquisition and Clampfit analysis software (version 10.1; Molecular 
Devices). AP traces were averaged using the Clampfit algorithm. The average traces were fitted by a Gaussian fit (three terms) in Clampfit.

Maxima derived by fitting were used to compare the relative time delays of paired groups of APs. Statistical analyses and illustrations of graphs were performed using Prism (GraphPad). Differences between groups were tested with an unpaired $t$ test. All in-text and graphic representations of data illustrate the mean $\pm \mathrm{SD}$. We also performed a linear regression analysis and computed Pearson product moment correlations for the data presented in Figure 3B.

\section{Results}

Here we show that conduction velocity differs dramatically and systematically in the two major axon collaterals of single NM axons to achieve submillisecond temporal accuracy of binaural activity onto the coincidence-detector NL neurons. Our anatomical measurements of axon diameter and nodes of Ranvier spacing (Seidl et al., 2010) suggest that individual axon segments interact with oligodendrocytes to adjust conduction velocity as needed for circuit function. In this report, we show that conduction velocities of the ipsilateral and contralateral collaterals of single NM axons differ systematically to compensate for anatomical restrictions imposed by axon lengths and developmental changes in head size, providing the microsecond precision necessary for binaural hearing.

We recorded aAPs elicited in individual NM neurons by stimulating electrodes placed at two different locations on the ipsilateral branch or on the contralateral branch of single $\mathrm{NM}$ axons [Fig. 1A, B, Ai and Bi (ipsilateral stimulation points), Ac and $\mathrm{Bc}$ (contralateral stimulation points)].

The NM neurons and their axons were labeled with biocytin to provide the material for a 3-D reconstruction of each stimulated axon. Stimulating electrodes were coated with $\mathrm{DiO}$ to determine their position along the axonal pathway and measure the distances between the stimulation sites. The time difference between the peaks of the aAPs (Fig. 1C) and the distance between the stimulation sites on individual axon collaterals were used to calculate the conduction velocity in the segment flanked by the stimulation electrodes.

By the time of hatching (E21), the chicken sound localization circuit is mature in anatomical and physiological properties (Reyes et al., 1994; Zhang and Trussell, 1994). Figure $1 C$ shows antidromic voltage responses of a representative NM neuron whose contralateral axon was stimulated at two different locations (Fig. 1C). On the left, 31 aAPs elicited by a stimulation electrode that was placed ipsilateral (Fig. $1 B, C$, position Ac, orange) are shown. The group of traces on the right shows 32 overlaid aAPs elicited by an electrode (Fig. $1 B, C$, position Bc, blue) contralateral to the midline on the same axon. The colored traces depict the respective average values of the two populations. Notice the low variability observed from trace to trace at the peak of the aAPs. In this example, the group of aAPs elicited by the more distal electrode arrived $475 \mu$ s later than the group of aAPs elicited by the electrode closer to the cell body. 3-D measurements along this axon revealed that the stimulation sites were $1594 \mu \mathrm{m}$ apart.

Figure $2 A$ shows a segment of a labeled axon (purple) and the position of the stimulating electrode (green). Figure 2, $B$ and $C$, shows representative examples of 3-D reconstructions of axons and NM neurons indicating the placement of stimulating electrodes.

Based on the time difference between aAPs and the distance along the axon between stimulation points, we calculated the velocity of signal propagation for the ipsilateral and the contralateral axons at room temperature. The average $( \pm \mathrm{SD})$ conduction

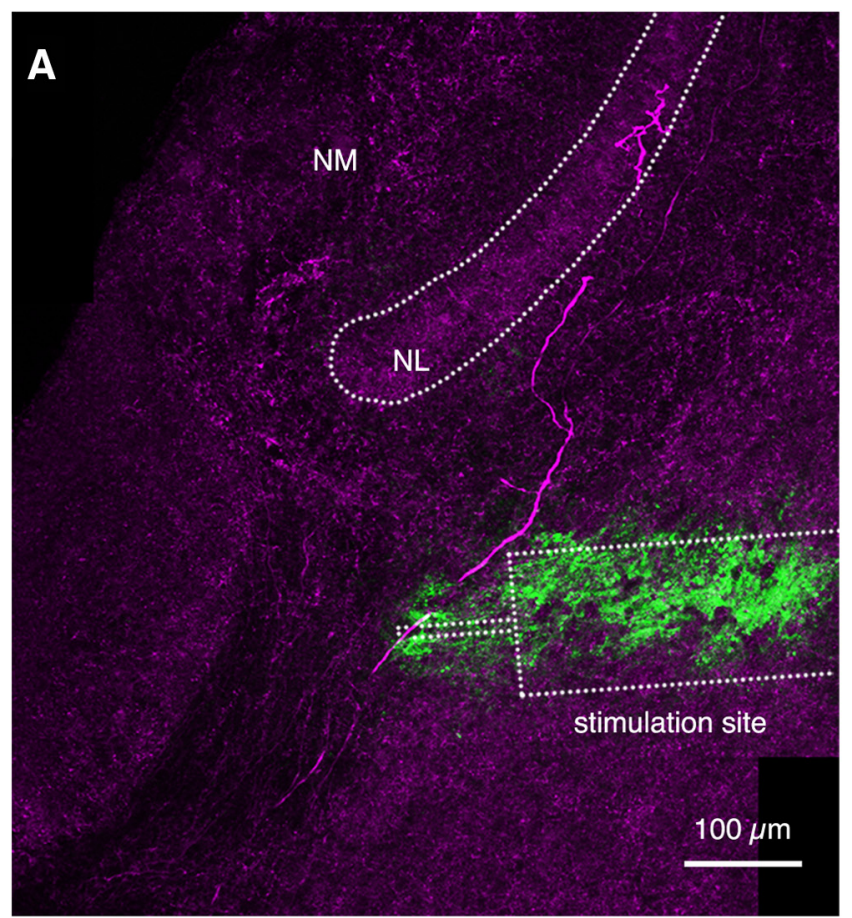

B
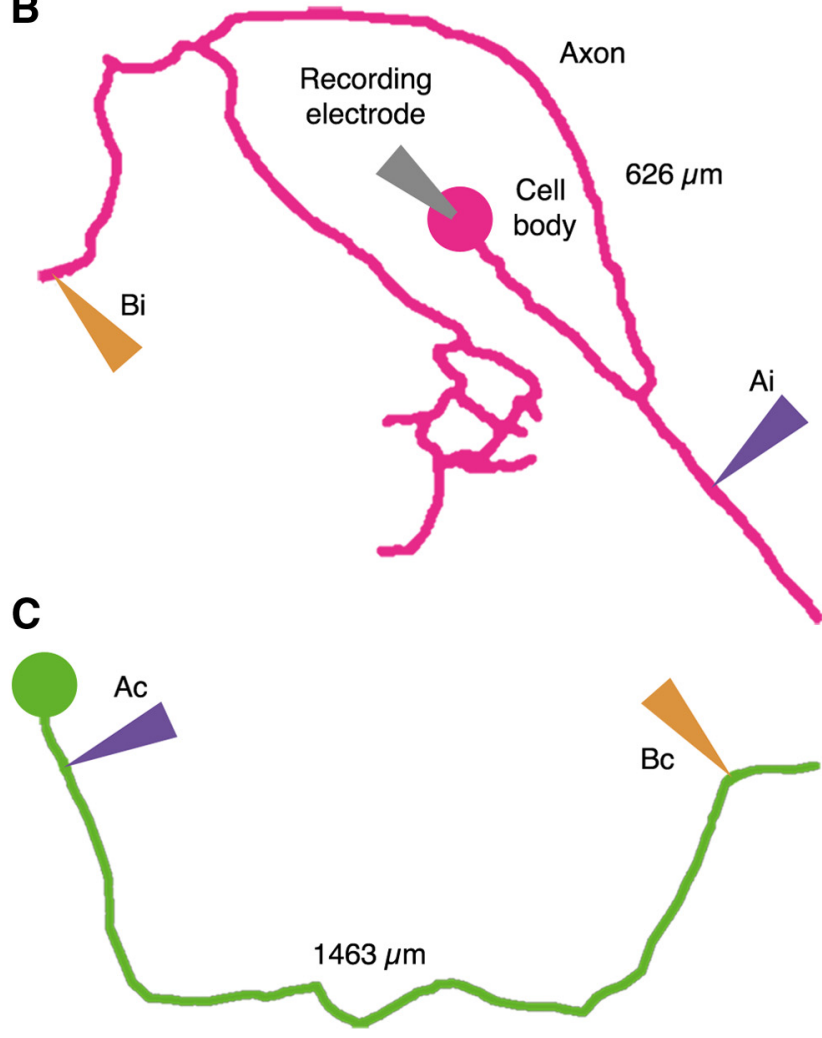

Figure 2. Distances between stimulation sites. $\boldsymbol{A}$, Projection image of a visualized axon (magenta) originating in the contralateral NM close to the target NL. The position of the stimulation electrode is identified by residual $\mathrm{DiO}$ (green). The outline of the stimulation electrode is indicated to scale. Tip diameter is $12.5 \mu \mathrm{m} . \boldsymbol{B}, \boldsymbol{C}, 3-\mathrm{D}$ reconstructions of stimulated ipsilateral NM axon $(\boldsymbol{B})$ and contralateral NM axon $(\boldsymbol{C})$ with stimulation sites indicated.

velocity was $1.59 \pm 0.34 \mathrm{~m} / \mathrm{s}(n=5)$ in the ipsilateral axon branch and $3.69 \pm 0.68 \mathrm{~m} / \mathrm{s}(n=6)$ in the contralateral axon branch $(p=0.0002$; Fig. $3 A$ ). Thus, the velocity of the action potential in the longer contralateral axon branch is on average more than twice the velocity found in the ipsilateral branch of the same cell. 

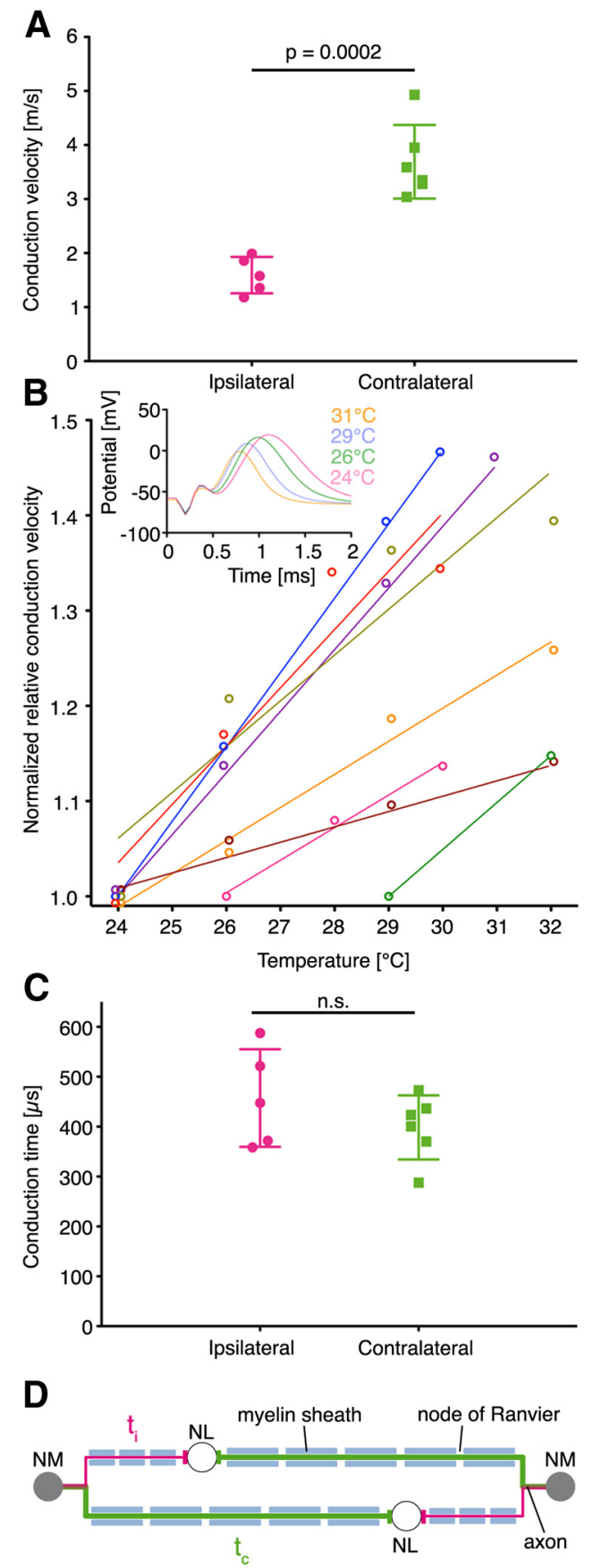

Figure 3. Differential regulation of conduction velocity in NM axon leads to equalization of conduction times. $A$, Different conduction velocities exist for ipsilateral $(n=5)$ and contralateral $(n=6)$ axonal branches. Error bars indicate SD; $p=0.0002 . B$, Conduction velocities as a function of temperature. Conduction velocity was measured in a given neuron at two to four different temperatures. Different colors depict different cells. Q10 values correlate to the steepness of the regression line, and ranged between 1.17 and 1.89 (mean, $1.53 \pm 0.23$ ). The relationship between temperature and conduction velocity for each cell was highly linear (mean $\left.r^{2}=0.96 \pm 0.05\right)$. Datapoints are nudged to prevent overlap. Inset, Example traces of aAP measured at different temperatures in the same neuron. C, Conduction times of the ipsilateral and the contralateral axonal branches from NM soma to terminals innervating $\mathrm{NL}$ are not statistically different. Mean values for calculated conduction times are $457 \pm 98 \mu$ s from the NM cell body to the ipsilateral NL and $399 \pm 64 \mu$ s from cell body to the most medial contralateral terminal. Error bars indicate SD. D, The ipsilateral and contralateral axon branches of the NM axon display widely different conduction velocities, compensating for a length difference $>1600 \mu \mathrm{m}$. Ipsilateral $\left(\mathrm{t}_{\mathrm{i}}\right)$ and contralateral $\left(\mathrm{t}_{\mathrm{c}}\right)$ conduction times achieve isochronicity $\left(t_{i}=t_{c}\right)$ in the microsecond range using variations in internode distance and axon diameter. In the shorter axon branch, internode distance and axon diameter are reduced relative to the longer axon branch. Magenta, Ipsilateral axon branch; green, contralateral axon branch.
It is important to establish the velocity of conduction at physiological temperatures to determine timing properties in behaviorally relevant conditions. To this end, we determined the Q10 for NM axons to assess conduction velocities at chicken body temperature. We measured conduction velocities of single axons while the preparation was held at different temperatures (Fig. 3B; $n=8)$. The correlation between temperature and conduction velocity measurements for each neuron was highly linear $\left(r^{2}=\right.$ $0.96 \pm 0.05 ; n=7)$. Q10 values ranged between 1.17 and 1.89 (mean, $1.53 \pm 0.23$ ), similar to what had been determined previously in the same axons (Overholt et al., 1992) and comparable to values determined by others in CNS axons of mammals (Swadlow et al., 1981). Using this Q10 value, we calculated the conduction velocities at physiological temperature for birds $\left(40^{\circ} \mathrm{C}\right)$ (Aschoff et al., 1973; Aronov and Fee, 2012). Conduction velocity at normal physiological temperature was estimated to be $3.36 \pm$ $0.70 \mathrm{~m} / \mathrm{s}$ for ipsilateral NM axon collaterals and $8.02 \pm 1.51 \mathrm{~m} / \mathrm{s}$ for contralateral axon collaterals. This extrapolation may overestimate the actual conduction velocity because high brain temperatures in birds could introduce nonlinear effects in the dynamics of the circuit (Hodgkin and Katz, 1949; Aronov and Fee, 2012). However, Overholt et al. (1992) showed a highly linear dependency of temperature up to $41^{\circ} \mathrm{C}$.

The conduction velocities at physiological temperatures combined with previously determined branch length measurements of NM axons (Seidl et al., 2010) allowed us to derive the absolute conduction times of the following axonal segments: (1) soma to the ipsilateral terminals innervating NL; and (2) soma to the most medial terminals innervating the contralateral NL (Fig. $1 A, B$ ). Using this information, the average conduction time from NM to the ipsilateral NL is $457 \pm 98 \mu \mathrm{s}$, and from NM to the medial region of the contralateral NL, $399 \pm 64 \mu \mathrm{s}$ (Fig. 3C). The difference between these values does not approach statistical significance $(p=0.26)$. Hence, differential regulation in conduction velocity counterbalances the difference in axon length and equalizes the conduction times of the main axon branches connecting individual NM neurons to the ipsilateral NL and the medial position of the contralateral NL (Fig. 3D).

\section{Discussion}

In individual segments of a single NM axon, conduction velocity is regulated systematically to achieve an equalization of conduction times to the ipsilateral NL and to the most medial NL neuron on the contralateral side of the brain. The resolution of this timing is in the microsecond range. In other words, anatomical restrictions imposed by axonal length are overcome by variations in axon diameter and internode distance, allowing isochronic inputs at NL and enabling the function of the delay line formed by the contralateral axon according to the model proposed by Jeffress (1948), and supported by numerous anatomical and physiological studies (Young and Rubel, 1983, 1986; Overholt et al., 1992; Köppl and Carr, 2008; Seidl et al., 2010). This equalization is required to achieve an array of coincident inputs whose function is to calculate ITDs that vary systematically as a function of the azimuthal position of a sound source, an essential step for sound segregation.

The relationships among axon caliber, myelination properties, and conduction velocity are well studied, and have been thoroughly documented over the past century. It is well known that axonal bifurcations usually result in a reduction in the caliber of each collateral and associated changes in conduction velocity (Rall, 1962; Waxman, 1975, 1980; Waxman and Swadlow, 1977). Previous studies in mammals have reported different conduction 
velocities in different branches of a peripheral sensory nerve (Wall, 1994; Durbaba et al., 2007) and in callosal axons in the CNS (Swadlow et al., 1980). In these cases, the functional interpretation is not clear, and the relationships among individual axons having different conduction velocities and their associated myelinating glia have not been studied. Our results take this concept one step further by demonstrating consistent and dramatic differences in conduction velocity between the two major projection collaterals of the same parent axon in the CNS. This result suggests local interactions of axon segments with oligodendrocytes to establish the appropriated conduction velocity. Of further significance, these differences are biologically meaningful in that they provide a mechanism for the establishment of isochronicity of signal propagation required for binaural processing of low-frequency acoustic signals.

Our results may help to understand the mammalian ITD detection circuit, consisting of neurons in the medial superior olive (MSO) and its binaural excitatory and inhibitory inputs. The exact mechanisms for understanding how this circuitry achieves the computation of azimuth is still a matter of debate (Joris and Yin, 2007; Grothe et al., 2010; Portfors and von Gersdorff, 2013), in particular the role of inhibition (Pecka et al., 2008; Roberts et al., 2013). However, recent in vivo whole-cell recordings from MSO neurons elegantly show that ITD tuning is determined by the timing of excitatory inputs (van der Heijden et al., 2013). Fine tuning of the conduction time of the axons providing these inputs by varying their diameter and internode distance may provide a mechanism to achieve this timing precision (Seidl et al., 2010).

Of more general interest is what our observations reveal about the interactions between neurons and glia cells. It remains unclear how specific internode distances and axonal diameters, both controlled by myelinating glia (de Waegh et al., 1992; Garcia et al., 2003; Court et al., 2004; Susuki and Rasband, 2008), are established or modulated during development. Recent evidence shows that myelination may be more dynamic than previously envisioned (Liu et al., 2012; Powers et al., 2013). In the chicken, myelination occurs around hearing onset (E14; Jackson and Rubel, 1978; Hartman et al., 1979; Macklin and Weill, 1985; Korn and Cramer, 2008) and at a time when synaptic activity is already present (E11; Jackson et al., 1982). Possible mechanisms for signaling between neurons and glia include electrical signaling. Electrical activity of CNS axons has been shown to affect the proliferation and differentiation of myelinating glia (Barres and Raff, 1993; Demerens et al., 1996; Stevens et al., 2002; Ishibashi et al., 2006; Káradóttir and Attwell, 2007; Wake et al., 2011). In the barn owl, myelination of NM axons occurs at a time when ITD tuning becomes stable, suggesting a role of myelin in fine-tuning the timing of the circuitry when binaural acoustic activity is present (Cheng and Carr, 2007). Interestingly, intracellular differences exist in oligodendrocytes as well. Ultrastructural studies show that myelin sheaths produced by different branches of the same oligodendrocyte differ across individual axons in the mammalian CNS (Waxman and Sims, 1984).

While variations of conduction velocity along axons are universally seen (Kimura and Itami, 2009; Seidl, 2013), the molecular signals regulating internode distance are still a mystery. Future experiments are needed to examine the developmental course of conduction times, what factors regulate the differential establishment of parameters determining signal propagation speed, and the molecular signals underlying the communication between axons and surrounding non-neuronal players. We have presented a biologically relevant example of precise differential regulation of conduction velocity in two major collaterals of a single neuron. We suggest that this system may be useful for further exploration of these cellular and molecular interactions.

\section{References}

Aronov D, Fee MS (2012) Natural changes in brain temperature underlie variations in song tempo during a mating behavior. PLoS One 7:e47856. CrossRef Medline

Aschoff C, Aschoff J, von Saint Paul U (1973) Circadian rhythms of chicken brain temperatures. J Physiol 230:103-113. Medline

Ashida G, Carr CE (2011) Sound localization: Jeffress and beyond. Curr Opin Neurobiol 21:745-751. CrossRef Medline

Barres BA, Raff MC (1993) Proliferation of oligodendrocyte precursor cells depends on electrical activity in axons. Nature 361:258-260. CrossRef Medline

Carr CE, Konishi M (1990) A circuit for detection of interaural time differences in the brain stem of the barn owl. J Neurosci 10:3227-3246. Medline

Cheng SM, Carr CE (2007) Functional delay of myelination of auditory delay lines in the nucleus laminaris of the barn owl. Dev Neurobiol 67: 1957-1974. CrossRef Medline

Court FA, Sherman DL, Pratt T, Garry EM, Ribchester RR, Cottrell DF, Fleetwood-Walker SM, Brophy PJ (2004) Restricted growth of Schwann cells lacking Cajal bands slows conduction in myelinated nerves. Nature 431:191-195. CrossRef Medline

Demerens C, Stankoff B, Logak M, Anglade P, Allinquant B, Couraud F, Zalc B, Lubetzki C (1996) Induction of myelination in the central nervous system by electrical activity. Proc Natl Acad Sci U S A 93:9887-9892. CrossRef Medline

de Waegh SM, Lee VM, Brady ST (1992) Local modulation of neurofilament phosphorylation, axonal caliber, and slow axonal transport by myelinating Schwann cells. Cell 68:451-463. CrossRef Medline

Durbaba R, Taylor A, Ellaway PH, Rawlinson S (2007) Spinal projection of spindle afferents of the longissimus lumborum muscles of the cat. J Physiol 580:659-675. CrossRef Medline

Garcia ML, Lobsiger CS, Shah SB, Deerinck TJ, Crum J, Young D, Ward CM, Crawford TO, Gotow T, Uchiyama Y, Ellisman MH, Calcutt NA, Cleveland DW (2003) NF-M is an essential target for the myelin-directed "outside-in" signaling cascade that mediates radial axonal growth. J Cell Biol 163:1011-1020. CrossRef Medline

Goldberg JM, Brown PB (1969) Response of binaural neurons of dog superior olivary complex to dichotic tonal stimuli: some physiological mechanisms of sound localization. J Neurophysiol 32:613-636. Medline

Grothe B, Pecka M, McAlpine D (2010) Mechanisms of sound localization in mammals. Physiol Rev 90:983-1012. CrossRef Medline

Hartman BK, Agrawal HC, Kalmbach S, Shearer WT (1979) A comparative study of the immunohistochemical localization of basic protein to myelin and oligodendrocytes in rat and chicken brain. J Comp Neurol 188:273290. CrossRef Medline

Hodgkin AL, Katz B (1949) The effect of temperature on the electrical activity of the giant axon of the squid. J Physiol 109:240-249. Medline

Ishibashi T, Dakin KA, Stevens B, Lee PR, Kozlov SV, Stewart CL, Fields RD (2006) Astrocytes promote myelination in response to electrical impulses. Neuron 49:823-832. CrossRef Medline

Jackson H, Rubel EW (1978) Ontogeny of behavioral responsiveness to sound in the chick embryo as indicated by electrical recordings of motility. J Comp Physiol Psychol 92:682-696. CrossRef Medline

Jackson H, Hackett JT, Rubel EW (1982) Organization and development of brain stem auditory nuclei in the chick: ontogeny of postsynaptic responses. J Comp Neurol 210:80-86. CrossRef Medline

Jeffress LA (1948) A place theory of sound localization. J Comp Physiol Psychol 41:35-39. CrossRef Medline

Joris P, Yin TC (2007) A matter of time: internal delays in binaural processing. Trends Neurosci 30:70-78. CrossRef Medline

Káradóttir R, Attwell D (2007) Neurotransmitter receptors in the life and death of oligodendrocytes. Neuroscience 145:1426-1438. CrossRef Medline

Kimura F, Itami C (2009) Myelination and isochronicity in neural networks. Front Neuroanat 3:12. CrossRef Medline

Köppl C, Carr CE (2008) Maps of interaural time difference in the chicken's brainstem nucleus laminaris. Biol Cybern 98:541-559. CrossRef Medline

Korn MJ, Cramer KS (2008) Distribution of glial-associated proteins in the developing chick auditory brainstem. Dev Neurobiol 68:1093-1106. CrossRef Medline 
Liu J, Dietz K, DeLoyht JM, Pedre X, Kelkar D, Kaur J, Vialou V, Lobo MK, Dietz DM, Nestler EJ, Dupree J, Casaccia P (2012) Impaired adult myelination in the prefrontal cortex of socially isolated mice. Nat Neurosci 15:1621-1623. CrossRef Medline

Macklin WB, Weill CL (1985) Appearance of myelin proteins during development in the chick central nervous system. Dev Neurosci 7:170-178. CrossRef Medline

Overholt EM, Rubel EW, Hyson RL (1992) A circuit for coding interaural time differences in the chick brainstem. J Neurosci 12:1698-1708. Medline

Parks TN, Rubel EW (1975) Organization and development of brain stem auditory nuclei of the chicken: organization of projections from n. magnocellularis to n. laminaris. J Comp Neurol 164:435-448. CrossRef Medline

Pecka M, Brand A, Behrend O, Grothe B (2008) Interaural time difference processing in the mammalian medial superior olive: the role of glycinergic inhibition. J Neurosci 28:6914-6925. CrossRef Medline

Portfors CV, von Gersdorff H (2013) Macrocircuits for sound localization use leaky coincidence detectors and specialized synapses. Neuron 78:755757. CrossRef Medline

Powers BE, Sellers DL, Lovelett EA, Cheung W, Aalami SP, Zapertov N, Maris DO, Horner PJ (2013) Remyelination reporter reveals prolonged refinement of spontaneously regenerated myelin. Proc Natl Acad Sci U S A 110:4075-4080. CrossRef Medline

Rall W (1962) Electrophysiology of a dendritic neuron model. Biophys J 2:145-167. CrossRef Medline

Reyes AD, Rubel EW, Spain WJ (1994) Membrane properties underlying the firing of neurons in the avian cochlear nucleus. J Neurosci 14:53525364. Medline

Roberts MT, Seeman SC, Golding NL (2013) A mechanistic understanding of the role of feedforward inhibition in the mammalian sound localization circuitry. Neuron 78:923-935. CrossRef Medline

Rubel EW, Parks TN (1975) Organization and development of brain stem auditory nuclei of the chicken: tonotopic organization of n. magnocellularis and n. laminaris. J Comp Neurol 164:411-433. CrossRef Medline

Sanchez JT, Seidl AH, Rubel EW, Barria A (2011) Preparation and culture of chicken auditory brainstem slices. J Vis Exp (49):2527. CrossRef

Sanchez JT, Seidl AH, Rubel EW, Barria A (2012) Control of neuronal excitability by NMDA-type glutamate receptors in early developing binaural auditory neurons. J Physiol 590:4801-4818. CrossRef Medline

Seidl AH (2013) Regulation of conduction time along axons. Neuroscience. Advance online publication. Retrieved March 6, 2014. doi:10.1016/j. neuroscience.2013.06.047. CrossRef Medline

Seidl AH, Rubel EW, Harris DM (2010) Mechanisms for adjusting interaural time differences to achieve binaural coincidence detection. J Neurosci 30:70-80. CrossRef Medline
Stevens B, Porta S, Haak LL, Gallo V, Fields RD (2002) Adenosine: a neuron-glial transmitter promoting myelination in the CNS in response to action potentials. Neuron 36:855-868. CrossRef Medline

Susuki K, Rasband MN (2008) Molecular mechanisms of node of Ranvier formation. Curr Opin Cell Biol 20:616-623. CrossRef Medline

Swadlow HA, Kocsis JD, Waxman SG (1980) Modulation of impulse conduction along the axonal tree. Annual review of biophysics and bioengineering 9:143-179. CrossRef Medline

Swadlow HA, Waxman SG, Weyand TG (1981) Effects of variations in temperature on impulse conduction along nonmyelinated axons in the mammalian brain. Exp Neurol 71:383-389. CrossRef Medline

van der Heijden M, Lorteije JA, Plauška A, Roberts MT, Golding NL, Borst JG (2013) Directional hearing by linear summation of binaural inputs at the medial superior olive. Neuron 78:936-948. CrossRef Medline

Wake H, Lee PR, Fields RD (2011) Control of local protein synthesis and initial events in myelination by action potentials. Science 333:1647-1651. CrossRef Medline

Wall PD (1994) Control of impulse conduction in long range branches of afferents by increases and decreases of primary afferent depolarization in the rat. Eur J Neurosci 6:1136-1142. CrossRef Medline

Wang Y, Sakano H, Beebe K, Brown MR, de Laat R, Bothwell M, Kulesza RJ, Rubel EW (2013) Intense and specialized dendritic localization of the fragile X mental retardation protein in binaural brainstem neurons-a comparative study in the alligator, chicken, gerbil, and human. J Comp Neurol. Advance online publication. Retrieved March 6, 2014. doi: 10.1002/cne.23520. CrossRef Medline

Waxman SG (1975) Integrative properties and design principles of axons. International review of neurobiology 18:1-40. CrossRef Medline

Waxman SG (1980) Determinants of conduction velocity in myelinated nerve fibers. Muscle Nerve 3:141-150. CrossRef Medline

Waxman SG, Sims TJ (1984) Specificity in central myelination: evidence for local regulation of myelin thickness. Brain Res 292:179-185. CrossRef Medline

Waxman SG, Swadlow HA (1977) The conduction properties of axons in central white matter. Prog Neurobiol 8:297-324. CrossRef Medline

Yin TC, Chan JC (1990) Interaural time sensitivity in medial superior olive of cat. J Neurophysiol 64:465-488. Medline

Young SR, Rubel EW (1983) Frequency-specific projections of individual neurons in chick brainstem auditory nuclei. J Neurosci 3:1373-1378. Medline

Young SR, Rubel EW (1986) Embryogenesis of arborization pattern and topography of individual axons in N. laminaris of the chicken brain stem. J Comp Neurol 254:425-459. CrossRef Medline

Zhang S, Trussell LO (1994) A characterization of excitatory postsynaptic potentials in the avian nucleus magnocellularis. J Neurophysiol 72:705718. Medline 